\title{
Health-related quality of life is not impaired in children with undetected as well as diagnosed celiac disease: a large population based cross-sectional study
}

Anna Myléus ${ }^{1 *}$, Solveig Petersen ${ }^{1,2}$, Annelie Carlsson ${ }^{3}$, Solveig Hammarroth ${ }^{4}$, Lotta Högberg 5,6 and Anneli Ivarsson ${ }^{1}$

\begin{abstract}
Background: Knowledge regarding the health-related quality of life (HRQoL) of children with celiac disease remains limited and inconclusive. We investigated the HRQoL of three groups of 12-year-olds with: i) undetected celiac disease ii) clinically diagnosed celiac disease, and iii) without celiac disease.

Methods: A school-based cross-sectional multicenter screening study invited 18325 children, whereof 68\% consented to participate. Participants provided a blood sample, which was later analyzed for anti-tissue-tranglutaminase antibodies, and alongside filled in a questionnaire. When anti-tissue-tranglutaminase antibodies were elevated, a small intestinal biopsy verified the screening-detected celiac disease diagnosis. Self-reported HRQoL was measured using Kidscreen, a generic 52 items instrument with proven reliability and validity. Scores were linearly transformed into a 0-100 scale with higher values indicating better HRQoL. Mean values with standard deviations (mean \pm SD) were compared, and uni- and multivariate logistic regression models tested the odds of a low HRQoL among children with undetected or diagnosed celiac disease, respectively.

Results: Children with undetected celiac disease $(n=238)$ reported similar HRQoL as children without celiac disease $(n=12037)(83.0 \pm 11.0$ vs. $82.5 \pm 11.3, P=0.51)$, and also similar HRQoL $(82.2 \pm 12.2, P=0.28)$ to that of children with diagnosed celiac disease $(n=90)$, of whom $92 \%$ were adherent to treatment. Having undetected celiac disease did not increase the odds of low overall HRQoL, independent of sex, area of residence, study year and occurrence of gastrointestinal symptoms (adjusted odds ratio $0.77,95 \% \mathrm{Cl} 0.54-1.10$ ). Comparable results were seen for diagnosed celiac disease cases (adjusted odds ratio 1.11, 95\% Cl 0.67-1.85).

Conclusion: Children with undetected celiac disease reported comparable HRQOL as their peers with diagnosed celiac disease, and those without celiac disease, when reporting prior to receiving the diagnosis through screening. Thus, children with celiac disease, both untreated and diagnosed, perceive their HRQoL as unimpaired by their disease.
\end{abstract}

Keywords: Celiac disease, Children, Health related quality of life, Kidscreen, Screening

\footnotetext{
*Correspondence: anna.myleus@epiph.umu.se

'Department of Public Health and Clinical Medicine, Epidemiology and

Global Health, Umeå University, Umeå, Sweden

Full list of author information is available at the end of the article
} 


\section{Background}

Celiac disease is one of the most common chronic diseases in childhood, affecting around 1\% of the population [1]. In some genetically predisposed individuals, dietary intake of gluten, found in wheat, ray, and barley, results in an immune-mediated small intestinal enteropathy [1-3]. Although the classical symptoms are related to the enteropathy (diarrhea, malnutrition, and failure to thrive), it has become evident that celiac disease can develop at any age with varying clinical presentations $[4,5]$. Especially when untreated, the disease has been associated with an increased risk of morbidity and mortality $[3,6,7]$. Serological markers indicative of untreated disease are in general use, but demonstration of small intestinal enteropathy remains the gold standard for diagnosis [8]. With treatment, a strict gluten-free diet, the serological markers normalize, the small intestinal mucosa recovers, and symptoms alleviate $[3,9]$. However, adhering to a strict gluten-free diet poses difficulties in everyday life including increased costs, social restrictions and stigmatisation, which may impact negatively on the health-related quality of life (HRQoL) [10-14].

Screening studies have shown that the majority of children with celiac disease are undiagnosed $[4,15,16]$, and mass screening might be an option for finding these cases [17]. The high rate of under-diagnosis has been attributed to the varying clinical presentation, where the classical gastrointestinal symptoms most commonly are either mild or lacking $[9,18]$. Children with undiagnosed celiac disease do not experience enough symptoms to receive correct diagnosis; however, it remains poorly understood whether these children are completely unaffected or if undiagnosed celiac disease affects the HRQoL.

HRQoL assessments have become increasingly important in health care and research as it offers a more comprehensive understanding of the disease impact for the individual compared to that of laboratory analyses and disease related symptoms alone [19]. HRQoL is defined as a multidimensional construct encompassing several areas of life; physical, emotional, mental, social and behavioural components of functioning and wellbeing, as perceived by the individual and/or others [20,21]. Several HRQoL instruments have been developed during the last decades, including a European cross-country instrument called Kidscreen [21,22].

In previous studies among adults, undetected celiac disease has been associated with reduced HRQoL, mostly with a subsequent improvement after initiation of treatment $[14,23]$. Such an improvement has also been seen among screening-detected cases [24,25], although the findings are inconsistent [14,23,24,26,27]. Most previous studies of HRQoL and celiac disease have been performed among adults and studies of HRQoL in children with celiac disease are limited and inconclusive [23,28-31].
In this study we investigated and compared the HRQoL assessed by the generic Kidscreen instrument in three groups of 12-year-olds with: i) undetected celiac disease at the data collection, who thereafter received the diagnosis through screening, ii) clinically diagnosed celiac disease, and iii) children without celiac disease.

\section{Methods}

\section{Design, procedure and study population}

This study emanated from a school-based, cross-sectional, screening study entitled ETICS (Exploring the Iceberg of Celiacs in Sweden), which has previously been described in detail elsewhere $[16,32,33]$. In brief, the study invited all children in grade six ( $\mathrm{n}=18325$; age $\sim 12$ years) attending schools in and around the five major Swedish cities Lund, Växjö, Norrköping, Norrtälje and Umeå during two oneyear periods starting in September 2005 and 2009, respectively. At enrollment, the parents reported whether their child had celiac disease diagnosed through routine clinical care prior to the study. All children were invited to provide a blood sample and alongside to fill in a questionnaire. Data collection was performed in the schools by research nurses with assistance from school health nurses and teachers [16,29]. Afterwards, blood samples were analyzed for serological markers; anti-tissue-transglutaminase antibodies of IgA-type (tTG) for all children and for some also anti-endomysial antibodies IgA (EMA), or in case of IgA-deficiency serological markers of IgG type. Children with elevated markers (tTG $>4 \mathrm{U} / \mathrm{mL}$, or tTG $2-4 \mathrm{U} / \mathrm{mL}$ combined with EMA $\geq 1: 5)$, but no previous diagnosis of celiac disease, were recommended a small intestinal biopsy at a close-by pediatric clinic [16,32]. Criteria for diagnosis were marked enteropathy (Marsh III), or the combination of milder enteropathy (Marsh I-II), HLADQ2 and/or DQ8 haplotype (genetic predisposition), symptoms and/or signs compatible with celiac disease, and clinical response to a gluten-free diet. Parental report of diagnosed celiac disease was confirmed through medical records and/or the National Swedish Childhood Celiac Disease Register following the same criteria.

The child's celiac disease status at data collection was classified as 'undetected celiac disease' if the analyses showed a biopsy fulfilling the celiac disease criteria, i.e. the child received the diagnosis through the screening. To be classified as having 'diagnosed celiac disease' the parental report was confirmed with a diagnosis fulfilling also our criteria. Children with normal serological markers were classified as 'without celiac disease'. In case of elevated serological markers in the screening but without biopsy-verified diagnosis (Marsh 0, Marsh I-II without other requirements, or small intestinal biopsy not performed) children were classified as having 'potential celiac disease'. 
A total of 13279 (72\%) parents and children gave informed consent to participate, and 12419 (68\%) children provided both blood samples and questionnaire data and were included in the current study (Figure 1). The study was approved by the Regional Ethical Review Board at Umeå University.

\section{Measures}

\section{Questionnaire}

HRQoL was assessed by the generic self-report version of the 52 item Kidscreen instrument [20-22]. This instrument measures overall HRQoL along with $10 \mathrm{HRQoL}$ subdomains capturing: physical well-being, psychological well-being, moods and emotions, self-perception, autonomy, parent relation and home life, financial resources, social support and peers, school environment, and social acceptance (bullying). Items utilize a 5-point response scale and a four week recall time. As recommended, scores were reversed and linearly transformed into a 0-100 scale with higher values indicating better HRQoL, and mean scores were estimated for all domains, given no more than one item were missing within the domain [20]. An exception was domains with only three items, i.e. financial resources and social acceptance, for which no missing were allowed. In the current study, items with multiple responses $(\mathrm{n}=1053,0.16 \%)$ were recoded as the mean if two adjacent responses, while other cases of

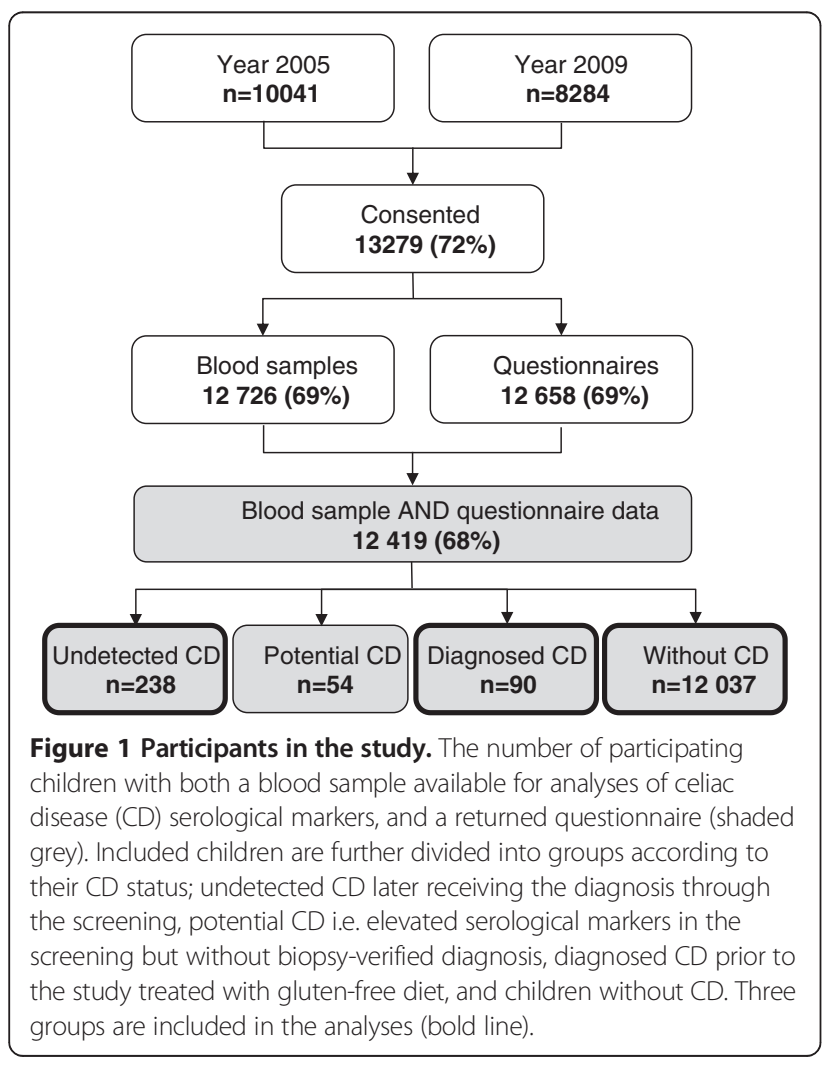

multiple responses were handled as missing. Overall HRQoL was only estimated for children with available scores within all 10 subdomains. Domain scores were described as low if below the lowest quartile ( $\leq 25$ percentile among the children without celiac disease) for the specific domain. The Kidscreen instrument has demonstrated acceptable levels of reliability and validity among children and adolescents in several countries including Sweden [21,22]. In this study population, the internal consistency was satisfactory (Cronbach's alpha $>0.7$ for all domains) both among children with celiac disease and those without.

Celiac disease associated gastrointestinal symptoms were measured by additional questions capturing eight symptoms: nausea, stomach ache, upset stomach, abdominal gas, bloating, hard stools, loose stools and poor appetite [34]. All responses were given on a 5-point scale ranging from never to always over the past six months. Presence of gastrointestinal symptom(s) was defined as having one or more symptom often or always.

\section{Blood samples for estimation of adherence}

For children with diagnosed celiac disease blood samples were analyzed for serological markers as estimation of adherence with the recommended treatment (gluten-free diet). The serological marker tTG were determined by enzyme-linked immunosorbent assay in accordance with manufacturer's instructions (Celikey, Phadia $\mathrm{GmbH}$, Freiburg, Germany) [16]. In these children, tTG $>5 \mathrm{U} / \mathrm{mL}$ was interpreted as non-adherence.

\section{Statistical analyses}

Microsoft Access 2010 (Microsoft, Redmond, WA) was used for handling the ETICS database and PASW Statistics versions 20 (SPSS Inc, Chicago, IL) to perform statistical analyses. Descriptive information was given as proportions and mean values with standard deviations $( \pm \mathrm{SD})$ or total range. Internal non-response for each subdomain were excluded, resulting in different number of children in each respective analyses (undetected celiac disease $n=227-237$, diagnosed celiac disease $n=87-90$, and children without celiac disease $n=11$ 517-11 963). Differences of HRQoL domain scores between children without celiac disease and undetected or diagnosed celiac disease, respectively, were tested by the MannWhitney U-test. This test was performed in the whole group and as well as after stratifications. Comparisons between proportions were performed by Chi-square test. Univariate and multivariate logistic regression models tested the odds of a low HRQoL score among children with undetected or diagnosed celiac disease compared to children without celiac disease. Multivariate models were adjusted for sex, study year (2005 or 2009), geographical area of residence (five areas), and the presence 
of gastrointestinal symptom(s) (yes or no). Statistical significance was defined as a two-tailed $\mathrm{P}<0.05$ corresponding to an odds ratio (OR) with a $95 \%$ confidence interval (CI) not including 1. For significant findings, the size of the difference was estimated using Cohen's d, defined as the difference in mean between the groups divided by the pooled SD, and interpreted as small if below 0.20 , moderate around 0.50 and large above 0.80 [35].

\section{Results}

\section{Characteristics of the participants}

Of the 12419 participating children with both blood samples and questionnaire data, 292 children without diagnosed celiac disease presented elevated serological markers. Of these 13 declined further investigation with small intestinal biopsy and 41 had a normal biopsy, leaving 238 children (137 girls) with undetected celiac disease at data collection (Figure 1). The 54 children with potential celiac disease were not further analysed in this sub-study. Among the remaining, 90 children (61 girls) were classified as having diagnosed celiac disease and they had been all recommended a gluten-free diet. Mean age $( \pm \mathrm{SD})$ at diagnosis was $4.7 \pm 4.0$ years and the majority ( $\mathrm{n}=83,92 \%)$ had normal tTG at data collection. Seven children revealed elevated $\mathrm{tTG}$, indicating nonadherence with the gluten-free diet (range 9.0-30 U/ml). They were not handled separately, since they were few and there was no correlation between tTG and HRQoL $\left(\mathrm{r}^{2}=0.24\right)$.

In Table 1 the characteristics of the participants stratified by celiac disease status is summarized. In 2005, a larger number of children were invited than in 2009 due to declining birth rates in Sweden. The largest study site was Lund [32]. Children with undetected celiac disease reported gastrointestinal symptoms equally commonly as the children without celiac disease $(21.1 \%$ vs. $21.8 \%$, $\mathrm{P}=0.80$ ). Of the children with diagnosed celiac disease $22.2 \%$ reported symptom (Table 1 ).

\section{HRQoL in children with celiac disease, undetected or diagnosed}

In general, the children reported relatively high HRQoL (mean \pm SD: $82.5 \pm 11.3$ ), with functioning and wellbeing in the 10 HRQoL subdomains ranging from a mean score of $76.4 \pm 17.1$ (school environment) to $92.0 \pm 14.7$ (social acceptance).

Children with undetected celiac disease reported comparable overall $\mathrm{HRQ}$ LL as their peers without celiac disease (mean \pm SD: $83.0 \pm 11.0$ vs. $82.5 \pm 11.3, \mathrm{P}=0.51$ ), and there was no difference between children with undetected and diagnosed celiac disease either (mean \pm SD: $83.0 \pm 11.0$ vs. $82.2 \pm 12.2, \mathrm{P}=0.28$ ). These findings were replicated in all HRQoL subdomains (Figure 2). Details are found in Additional file 1: Table S1. Moreover, having undetected
Table 1 Characteristics of the participating children stratified by celiac disease (CD) status

\begin{tabular}{|c|c|c|c|}
\hline Characteristics (\%) & $\begin{array}{l}\text { Undetected } \\
\qquad \begin{array}{c}C^{1} \\
N=238\end{array}\end{array}$ & $\begin{array}{c}\text { Diagnosed } \\
\qquad D^{2} \\
N=90\end{array}$ & $\begin{array}{c}\begin{array}{c}\text { Without } \\
\text { CD }\end{array} \\
\mathrm{N}=12037\end{array}$ \\
\hline \multicolumn{4}{|l|}{ Sex } \\
\hline Girls & 58 & 68 & 49 \\
\hline Boys & 42 & 32 & 51 \\
\hline \multicolumn{4}{|l|}{ Year } \\
\hline 2005 & 63 & 66 & 57 \\
\hline 2009 & 37 & 34 & 43 \\
\hline
\end{tabular}

Geographical

area of residence

Lund

Växjö

Norrköping

Norrtälje

Umeå

$\begin{array}{lcc}42 & 48 & 44 \\ 20 & 14 & 14 \\ 11 & 17 & 12 \\ 13 & 4 & 11 \\ 14 & 17 & 18\end{array}$

Gastrointestinal symptoms

\begin{tabular}{llll} 
No & 79 & 78 & 78 \\
Yes & 21 & 22 & 22 \\
\hline
\end{tabular}

${ }^{1}$ At the data collection CD was undetected, later diagnosed through screening. ${ }^{2} \mathrm{CD}$ diagnosed through routine clinical care prior to the study.

celiac disease did not increase the odds of low overall functioning and wellbeing, independent of sex, area of residence, study year and occurrence of gastrointestinal symptoms (adjusted OR 0.77, 95\% CI 0.54-1.10). Similarly, we found no increased unadjusted or adjusted odds in any separate HRQoL subdomain (Table 2).

Children with diagnosed celiac disease also reported similar overall HRQoL as children without celiac disease (mean \pm SD: $82.2 \pm 12.2$ vs. $82.5 \pm 11.3, \mathrm{P}=0.29$ ). Again, the findings were replicated in all $10 \mathrm{HRQoL}$ subdomains studied (Figure 2). Diagnosed celiac disease was not associated with low overall functioning and wellbeing. Adjusting for sex, area of residence, study year and gastrointestinal symptoms did not affect the finding (adjusted OR 1.11, 95\% CI 0.67-1.85) and similar results were seen for all 10 HRQoL subdomains (Table 2).

Considering the HRQoL stratified by sex showed no differences between children with and without celiac disease (Figure 3), although girls reported lower HRQoL than boys, except for the domains of social support and peers, and school environment which had the opposed relationship. Children reporting gastrointestinal symptoms also reported lower HRQoL than those without symptoms. Stratified analyses showed no HRQoL difference between children with and without celiac disease independent of the occurrence gastrointestinal symptoms (Figure 3). The study was performed in two phases 


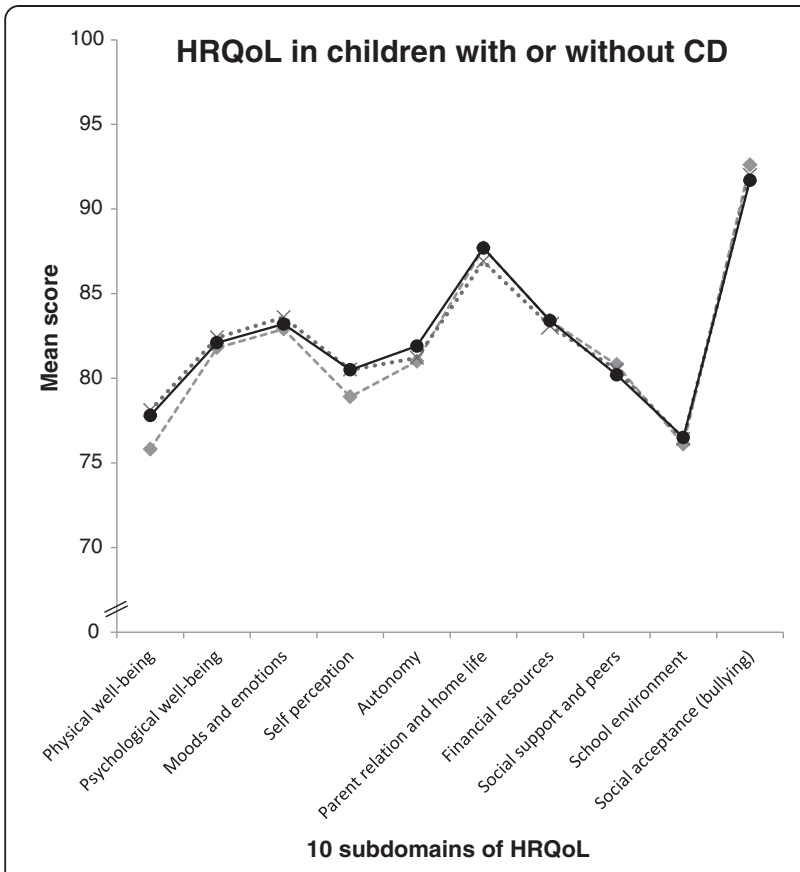

Figure $2 \mathrm{HRQ}$ oL in children with and without celiac disease. Health-related quality of life (HRQoL) profiles assessed with the Kidscreen-52 subdomains for the three groups of children; with undetected or diagnosed celiac disease (CD), and without CD (non-CD). We observed no statistically significant difference in any subdomain.

and the HRQoL among the children was somewhat higher in 2005 compared to 2009, however, the effect size was neglectable (Cohen's d <0.1) (Additional file 2: Table S2) and the two groups were handled as one.

\section{Discussion}

In this large population based study in Sweden, children with undetected celiac disease reported similar HRQoL as children with diagnosed celiac disease. These children also reported HRQoL comparable to Swedish children without celiac disease. Accordingly, children with undetected or diagnosed celiac disease were not at increased odds for having low HRQoL. To the best of our knowledge, this is the first large population based study capturing the HRQoL of children with both undetected and diagnosed celiac disease by use of a comprehensive standardized HRQoL measure.

A previous population based study from our group, found no HRQoL difference between 153 school aged children with undetected celiac disease and children without celiac disease, when investigating self-reported HRQoL by the shorter six item EQ-5D-Y HRQoL instrument [29]. In the current study we confirmed these results in an extended study group (238 12-year old children with undetected celiac disease) and by use of a more comprehensive assessment of HRQoL (full-form
52 item Kidscreen instrument). These findings thus suggest that HRQoL is not impaired in school aged children with undetected celiac disease.

One study in younger children is however partly contradictive. This study found lower parent-reported HRQoL in children diagnosed through screening at age 2-4 years, but only among the children with gastrointestinal symptoms; children without symptoms had similar HRQoL as a population based reference group [36]. In our study, stratifying for gastrointestinal symptoms did not affect the results. The issue of gastrointestinal symptoms in children with celiac disease is however complicated. In a qualitative study from our group it was shown that school aged children diagnosed with celiac disease through screening in retrospect realized that they had experienced a varying degree of symptoms associated with the undetected disease, which they were not aware of prior to treatment [13]. Similarly, among children who were diagnosed with celiac disease through screening in at-risk groups, $50 \%$ of those with no symptoms at diagnosis reported alleviation of symptoms after one year of treatment [28], further indicating that unawareness of celiac disease related symptoms prior to treatment is common among children. This adaption to symptoms related to celiac disease in childhood may partly explain the lack of HRQoL impairment in children with undetected celiac disease when they report prior to knowledge of the disease.

Our findings of an unimpaired self-reported HRQoL in children with undetected celiac disease contributes to an understanding of why most celiac disease cases are not identified in clinical practice. Despite moderate to severe enteropathy $[16,32]$, they are not presenting an affected overall HRQoL, and children with a low HRQoL do not have higher odds of undetected celiac disease than other children. Thus, mass screening using serological markers might be necessary to identify all cases of celiac disease. However, the issue of mass screening is still controversial and more research is needed before it can be determined whether it is an appropriate public health intervention or not $[3,17]$.

In our study also children with diagnosed celiac disease reported HRQoL corresponding to that of children without celiac disease. This finding has been seen also in other studies $[29,36,37]$, although previous findings are not conclusive. Inconclusive findings could originate from different methods for assessing HRQoL, especially when taking different aspects of HRQoL into account. Domains more linked to feeding and socialization have been shown to be more impaired due to the gluten-free diet $[30,31,38]$. In line with these findings we saw the highest odds for low HRQoL among children with diagnosed celiac disease in the subdomain school environment, although the difference was not statistically 
Table 2 Odds of low health-related quality of life (HRQOL) in children with undetected and diagnosed celiac disease (CD) compared with children without CD

\begin{tabular}{lccc}
\hline HRQoL $^{1}$ & Low HRQoL & Crude & Adjusted \\
& $n(\%)^{2}$ & OR $(95 \% \mathrm{Cl})^{3}$ & OR $(95 \% \mathrm{Cl})^{4}$ \\
& & &
\end{tabular}

Physical well-being

Without $C D^{5}$

Undetected $C D^{6}$

Diagnosed $C D^{7}$

3491 (29.6)

1

$66(28.3)$

$0.94(0.71-1.26) \quad 0.93(0.69-1.27)$

Psychological

well-being

Without $C D$

Undetected $C D$

Diagnosed CD

Moods and

emotions

Without CD

Undetected $C D$

Diagnosed CD

Self-perception

Without CD

Undetected CD

Diagnosed CD

Autonomy

Without CD

Undetected CD

Diagnosed CD

Parent relation

and home life

Without CD

Undetected CD

Diagnosed CD

Financial resources

Without CD

Undetected CD

Diagnosed CD

Social support

and peers

Without CD

Undetected CD

Diagnosed CD

School environment

Without CD

Undetected $C D$

Diagnosed CD

$30(33.7) \quad 1.21(0.78-1.88) \quad 1.29(0.81-2.06)$
3501 (29.7)

69 (29.6)

28 (31.5)

$3169(26.8)$

$58(25.0)$

$24(26.7)$

$3372(28.2)$

$60(25.5)$

$32(35.6)$

3015 (25.2)

49 (20.7)

$22(24.7)$

2469 (20.8)

45 (19.2)

16 (18.0)

4048 (34.8)

75 (33.0)

31 (35.2)

$2403(20.2)$

41 (17.4)

$19(21.1)$

$0.83(0.59-1.17) \quad 0.92(0.65-1.30)$

$1.06(0.64-1.76) \quad 1.30(0.77-2.19)$

$2527(21.9)$

$44(19.0)$

$24(27.6)$

$0.99(0.75-1.32) \quad 0.98(0.73-1.34)$

$1.09(0.69-1.70) \quad 1.14(0.71-1.82)$

$\begin{array}{cc}1 & 1 \\ 0.91(0.67-1.23) & 0.85(0.62-1.18)\end{array}$

$0.99(0.62-1.59) \quad 1.0(0.61-1.65)$

$0.87(0.65-1.17) \quad 0.79(0.58-1.09)$

$1.41(0.91-2.17) \quad 1.15(0.72-1.86)$

$0.77(0.56-1.06) \quad 0.74(0.53-1.03)$

$0.97(0.60-1.58) \quad 0.96(0.57-1.60)$

$0.91(0.65-1.26) \quad 0.85(0.60-1.21)$

$0.83(0.49-1.44) \quad 0.92(0.52-1.60)$

$92(0.70-1.22) \quad 0.84(0.63-1.13)$

$1.02(0.66-1.58) \quad 0.94(0.59-1.51)$
Table 2 Odds of low health-related quality of life (HRQoL) in children with undetected and diagnosed celiac disease (CD) compared with children without CD (Continued)

Social acceptance (bullying)

$\begin{array}{llll}\text { Without } C D & 2499(21.7) & 1 & 1\end{array}$

Undetected CD $\quad 52(22.6) \quad 1.05(0.77-1.44) \quad 1.06(0.76-1.47)$

Diagnosed CD $\quad 14(16.1) \quad 0.69(0.39-1.23) \quad 0.72(0.39-1.31)$

${ }^{1} \mathrm{HRQ}$ oL was assessed using the Kidscreen-52 instrument.

${ }^{2}$ Low HRQoL was defined as the children reporting a score in the lowest quartile. Number and proportion of children reporting low HRQoL, excluding internal non-response for each respective subdomain.

${ }^{3}$ Univariate logistic regression giving the odds ratio (OR) with $95 \%$ confidence interval $(\mathrm{Cl})$.

${ }^{4}$ Multivariate logistic regression model including sex, phase of the study, geographical area, and presence of gastrointestinal symptoms.

${ }^{5}$ Children with normal serological markers $(\mathrm{N}=12037)$.

${ }^{6}$ At the collection of the HRQoL data CD was undetected $(N=238)$, later diagnosed through screening.

${ }^{7} \mathrm{CD}$ diagnosed through routine clinical care prior to the study $(\mathrm{N}=90)$.

significant (Table 2). A celiac disease specific HRQoL instrument focuses in detail on aspects affected by the gluten-free diet and could therefore be more sensitive than a generic instrument $[23,38]$. Thus, we cannot exclude that our findings could, at least partly, be explained by a failure of the generic instrument Kidscreen to fully capture if diagnosed celiac disease affects HRQoL.

It has been shown that adherence with the gluten-free diet is important for obtaining similar HRQoL among children with celiac disease as their peers [39]. However, the burden of following a strict gluten-free diet has been associated with reduced HRQoL [40]. In our study, adherence with the gluten-free diet was high (92\%) in comparison with other studies $[14,31,41]$. However, occasional gluten intake might not be captured by elevated tTG resulting in overestimation of the adherence. We were also limited by the cross-sectional study design where inference whether non-adherence affected HRQoL, or if children with low HRQoL due to other reasons did not manage to adhere to the gluten-free diet, could not be made. Therefore, we did not further investigate the influence of adherence on HRQoL in our study. Larger longitudinal studies investigating the influence of treatment adherence on HRQoL, and visa verse, are warranted.

A strength of our study was that it was based on an actual population-based screening study. Thus, the children with undetected celiac disease emanated from the general population, and in contrast to several other studies, we were able to assess the HRQoL prior to the diagnosis of screening-detected celiac disease [23,28]. Moreover, the children with diagnosed celiac disease were also identified from the general population, compared to the more common recruitment through patient societies [23]. As there may be a selection in who joins a patient society, the current strategy is likely to give a more accurate description of HRQoL in children with diagnosed celiac disease. The population-based strategy, however, also constituted a 


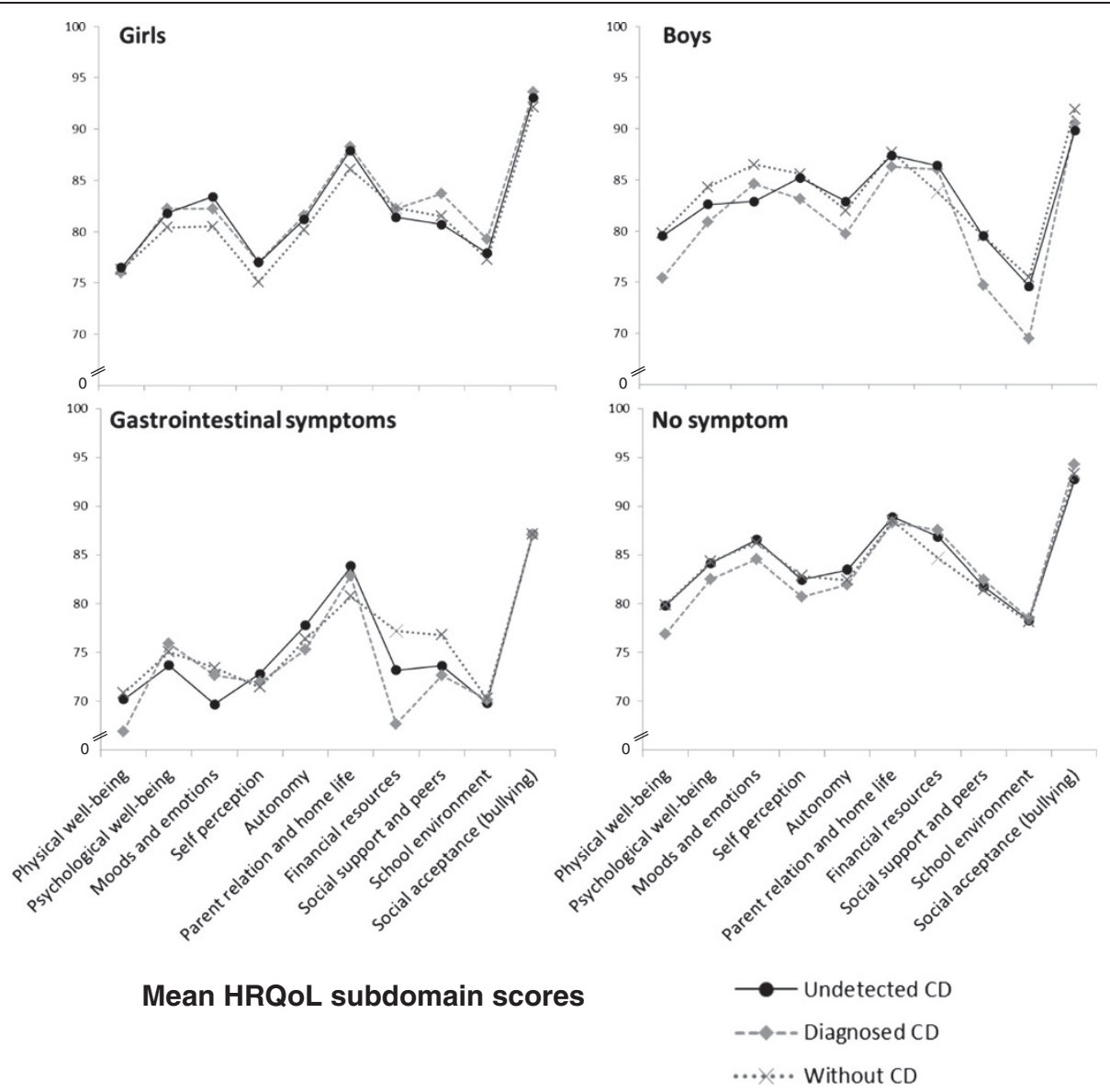

Figure $3 \mathrm{HRQ}$ oL in children with and without celiac disease, stratified by sex and gastrointestinal symptoms. Health-related quality of life (HRQoL) profiles by Kidscreen-52 subdomains for the three groups of children; with undetected or diagnosed celiac disease (CD), and without CD (non-CD) stratified by sex and presence of gastrointestinal symptoms (yes or no). Overall, girls and children with gastrointestinal symptoms reported lower HRQoL but we observed no difference between the three groups in any subdomain in any strata.

limitation. Albeit a relatively large cohort ( $\mathrm{n}=12419$ participants) the number of children with celiac disease were limited and we cannot exclude that lack of power affected our findings, especially after stratifications. The participants comprised $69 \%$ of all invited children in sixth grade. Their HRQoL were comparable to the that found by the Swedish National Institute of Public Health when they performed a countrywide, all-encompassing survey using the same HRQoL instrument, during the same time period, and in the same age group [42]. This suggests that our HRQoL results are representative for 12-year-old children in Sweden, and due to the homogeneity of the Swedish society, the association between HRQoL and celiac disease likely is the same across the country. The lack of adjustment for socioeconomic status may, however, constitute a potential limitation. Socioeconomic status is negatively associated with HRQoL [43], and might be associated with celiac disease, thereby constituting a potential confounder. However, the relationship between socioeconomic status and celiac disease has contradictory findings also from Sweden [44-46], with the largest study rejecting an association [47]. To the best of our knowledge, the only previous study which has tested the potential influence of socioeconomic status on HRQoL in celiac disease did not find an association between the two [48].

\section{Conclusion}

Children with undetected and thereby untreated celiac disease reported comparable HRQoL as their peers when reporting prior to receiving the celiac disease diagnosis through screening. They also reported similar HRQoL as children with diagnosed celiac disease. Thus, children with diagnosed and treated celiac disease may be able to attain the same HRQoL as their peers without the disease. HRQoL encompasses several areas of functioning and wellbeing, and the current study suggests that children with celiac disease, both undetected and diagnosed, perceive unimpaired functioning and wellbeing within all such areas of HRQoL. 


\section{Additional files}

Additional file 1: Table S1. Details of findings presented in Figure 2.

Additional file 2: Table S2. Comparisons of health-related quality of life (HRQOL) between data collections 2005 and 2009.

\section{Abbreviations}

Cl: Confidence interval; EMA: Anti-endomysial antibodies IgA; ETICS: Exploring the Iceberg of Celiacs in Sweden - screening study; HRQoL: Health-related quality of life; OR: Odds ratio; SD: Standard deviation; tTG: Anti-tissue-transglutaminase antibodies $\lg \mathrm{A}$

\section{Competing interests}

The authors declare that they have no competing interests.

\section{Authors' contribution}

All authors contributed to the conception, design and planning of the study, and to the data collection. AM performed the statistical analyses, interpretation of data, and wrote the first draft and the final manuscript. SP contributed to the statistical analyses, data interpretation, and writing of the manuscript. Al was principal investigator of the study. All authors reviewed the manuscript critically and approved its final version.

\section{Acknowledgement}

We thank all participating children and their families; and personnel working with the study: research nurses, laboratory personnel and administrative staff, and collaborators within the school health services and pediatric departments. We also thank Eva Karlsson, MD in Växjö, Lars Stenhammar, MD, PhD in Norrköping, and Lars Danielsson, MD in Norrtälje for valuable contribution to the planning of the study and the data collection. The study was performed in cooperation with the county councils of Västerbotten, Stockholm, Östergötland, Kronoberg, and Skåne. The study was undertaken within the Umeå Centre for Global Health Research at Umeå University, which is support by FORTE, the Swedish Research Council for Health, Working Life and Wellfare. The study was funded by the European Union supported project FP6-2005-FOOD-4B-36383-PREVENTCD, the Swedish Research Council (grants 521-2004-7093, 521-2007-2953), the Swedish Research Council for Environment, Agricultural Sciences and Spatial Planning (grants 222-2004-1918 and 222-2007-1394), and the Swedish Council for Working Life and Social Research (grant 2005-0802). The first author received funding for working with the manuscript from the Swedish Celiac Disease Society and from the Oskar foundation.

\section{Author details}

'Department of Public Health and Clinical Medicine, Epidemiology and Global Health, Umeå University, Umeå, Sweden. ${ }^{2}$ Department of Clinical Sciences, Child and Adolescent Psychiatry, Umeå University, Umeå, Sweden. ${ }^{3}$ Department of Pediatrics, Clinical Sciences, Skånes University Hospital, Lund University, Lund, Sweden. ${ }^{4}$ Pediatric Clinic, Norrtälje Hospital, Norrtälje, Swedens. ${ }^{5}$ Department of Pediatrics in Norrköping, County Council of Östergötland, Norrköping, Sweden. ${ }^{6}$ Department of Clinical and Experimental Medicine, Faculty of Health Sciences, Division of Pediatrics, Linköping University, Linköping, Sweden.

Received: 17 January 2014 Accepted: 24 April 2014

Published: 5 May 2014

\section{References}

1. Green PH, Cellier C: Celiac disease. N Engl J Med 2007, 357(17):1731-1743.

2. Ludvigsson JF, Leffler DA, Bai JC, Biagi F, Fasano A, Green PH, Hadjivassiliou M, Kaukinen K, Kelly CP, Leonard JN, Lundin KE, Murray JA, Sanders DS, Walker MM, Zingone F, Ciacci C: The Oslo definitions for coeliac disease and related terms. Gut 2013, 62(1):43-52.

3. di Sabatino A, Corazza GR: Coeliac disease. Lancet 2009, 373(9673):1480-1493.

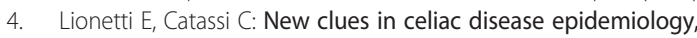
pathogenesis, clinical manifestations, and treatment. Int Rev Immunol 2011, 30(4):219-231.

5. Zawahir S, Safta A, Fasano A: Pediatric celiac disease. Curr Opin Pediatr 2009, 21(5):655-660
6. Tio M, Cox MR, Eslick GD: Meta-analysis: coeliac disease and the risk of all-cause mortality, any malignancy and lymphoid malignancy. Aliment Pharmacol Ther 2012, 35(5):540-551.

7. Ludvigsson JF: Mortality and malignancy in celiac disease. Gastrointest Endosc Clin N Am 2012, 22(4):705-722

8. Husby S, Koletzko S, Korponay-Szabo IR, Mearin ML, Phillips A, Shamir R, Troncone R, Giersiepen K, Branski D, Catassi C, Lelgeman M, Maki M, Ribes-Koninckx C, Ventura A, Zimmer KP, Espghan Working Group on Coeliac Disease Diagnosis, Espghan Gastroenterology Committee, European Society for Pediatric Gastroenterology, Hepatology and Nutrition: European Society for Pediatric Gastroenterology, Hepatology and Nutrition guidelines for the diagnosis of coeliac disease. J Pediatr Gastroenterol Nutr 2012, 54(1):136-160

9. Rizkalla Reilly N, Dixit R, Simpson S, Green PH: Celiac disease in children: an old disease with new features. Minerva Pediatr 2012, 64(1):71-81.

10. Lee $\mathrm{AR}, \mathrm{Ng} \mathrm{DL}$, Zivin J, Green PH: Economic burden of a gluten-free diet. J Hum Nutr Diet 2007, 20(5):423-430.

11. Black $\lrcorner$, Orfila C: Impact of coeliac disease on dietary habits and quality of life. J Hum Nutr Diet 2011, 24(6):582-587.

12. Olsson C, Lyon P, Hornell A, Ivarsson A, Sydner YM: Food that makes you different: the stigma experienced by adolescents with celiac disease. Qual Health Res 2009, 19(7):976-984.

13. Rosen A, Ivarsson A, Nordyke K, Karlsson E, Carlsson A, Danielsson L, Hogberg L, Emmelin M: Balancing health benefits and social sacrifices: a qualitative study of how screening-detected celiac disease impacts adolescents' quality of life. BMC Pediatr 2011, 11:32.

14. Aggarwal S, Lebwohl B, Green PH: Screening for celiac disease in averagerisk and high-risk populations. Ther Adv Gastroenterol 2012, 5(1):37-47.

15. Dube C, Rostom A, Sy R, Cranney A, Saloojee N, Garritty C, Sampson M, Zhang L, Yazdi F, Mamaladze V, Pan I, Macneil J, Mack D, Patel D, Moher D: The prevalence of celiac disease in average-risk and at-risk Western European populations: a systematic review. Gastroenterology 2005, 128(4 Suppl 1):S57-67

16. Myleus A, Ivarsson A, Webb C, Danielsson L, Hernell O, Hogberg L, Karlsson E, Lagerqvist C, Norstrom F, Rosen A, Sandstrom O, Stenhammar L, Stenlund H, Wall S, Carlsson A: Celiac disease revealed in 3\% of Swedish 12-year-olds born during an epidemic. J Pediatr Gastroentero/ Nutr 2009, 49(2):170-176.

17. Mearin ML, Ivarsson A, Dickey W: Coeliac disease: is it time for mass screening? Best Pract Res Clin Gastroenterol 2005, 19(3):441-452.

18. Rashid M, Cranney A, Zarkadas M, Graham ID, Switzer C, Case S, Molloy M, Warren RE, Burrows V, Butzner JD: Celiac disease: evaluation of the diagnosis and dietary compliance in Canadian children. Pediatrics 2005, 116(6):e754-e759.

19. Testa MA, Simonson DC: Assesment of quality-of-life outcomes. N Engl J Med 1996, 334(13):835-840.

20. The Kidscreen Group Europe: The KIDSCREEN Questionnaires, Quality of life questionnaires for children and adolescents. In Handbook. Lengerich: Pabst Science Publishers; 2006.

21. Ravens-Sieberer U, Herdman M, Devine J, Otto C, Bullinger M, Rose M, Klasen F: The European KIDSCREEN approach to measure quality of life and well-being in children: development, current application, and future advances. Qual Life Res 2014, 23(3):791-803.

22. Ravens-Sieberer $U$, Gosch A, Rajmil L, Erhart M, Bruil J, Duer W, Auquier $P$ Power M, Abel T, Czemy L, Mazur J, Czimbalmos A, Tountas Y, Hagquist C, Kilroe J, Kidscreen Group E: KIDSCREEN-52 quality-of-life measure for children and adolescents. Expert Rev Pharmacoecon Outcomes Res 2005 5(3):353-364.

23. Kurppa K, Collin P, Maki M, Kaukinen K: Celiac disease and health-related quality of life. Expert Rev Gastroenterol Hepatol 2011, 5(1):83-90

24. Ukkola A, Maki M, Kurppa K, Collin P, Huhtala H, Kekkonen L, Kaukinen K. Diet improves perception of health and well-being in symptomatic, but not asymptomatic, patients with celiac disease. Clin Gastroenterol Hepatol 2011, 9(2):118-123

25. Mustalahti K, Lohiniemi S, Collin P, Vuolteenaho N, Laippala P, Maki M: Gluten-free diet and quality of life in patients with screen-detected celiac disease. Eff Clin Pract 2002, 5(3):105-113.

26. Johnston SD, Rodgers C, Watson RG: Quality of life in screen-detected and typical coeliac disease and the effect of excluding dietary gluten. Eur J Gastroenterol Hepatol 2004, 16(12):1281-1286.

27. Viljamaa M, Collin P, Huhtala H, Sievanen H, Maki M, Kaukinen K: Is coeliac disease screening in risk groups justified? A fourteen-year follow-up with 
special focus on compliance and quality of life. Aliment Pharmacol The 2005, 22(4):317-324.

28. Kinos S, Kurppa K, Ukkola A, Collin P, Lahdeaho ML, Huhtala H, Kekkonen L, Maki M, Kaukinen K: Burden of illness in screen-detected children with celiac disease and their families. J Pediatr Gastroenterol Nutr 2012, 55(4):412-416

29. Nordyke K, Norstrom F, Lindholm L, Carlsson A, Danielsson L, Emmelin M, Hogberg L, Karlsson E, Ivarsson A: Health-related quality-of-life in children with coeliac disease, measured prior to receiving their diagnosis through screening. J Med Screen 2011, 18(4):187-192.

30. de Lorenzo CM, Xikota JC, Wayhs MC, Nassar SM, de Souza Pires MM: Evaluation of the quality of life of children with celiac disease and their parents: a case-control study. Qual Life Res 2012, 21(1):77-85.

31. Altobelli E, Paduano R, Gentile T, Caloisi C, Marziliano C, Necozione S, di Orio F: Health-related quality of life in children and adolescents with celiac disease: survey of a population from central Italy. Health Qual Life Outcomes 2013, 11:204

32. Ivarsson A, Myleus A, Norstrom F, van der Pals M, Rosen A, Hogberg L, Danielsson L, Halvarsson B, Hammarroth S, Hernell O, Karlsson E, Stenhammar L, Webb C, Sandstrom O, Carlsson A: Prevalence of childhood celiac disease and changes in infant feeding. Pediatrics 2013, 131(3):e687-e694.

33. Webb C, Halvarsson B, Norstrom F, Myleus A, Carlsson A, Danielsson L, Hogberg L, Ivarsson A, Karlsson E, Stenhammar L, Sandstrom O: Accuracy in celiac disease diagnostics by controlling the small-bowel biopsy process. J Pediatr Gastroenterol Nutr 2011, 52(5):549-553.

34. Rosen A, Sandstrom O, Carlsson A, Hogberg L, Olen O, Stenlund H, Ivarsson A: Usefulness of symptoms to screen for celiac disease. Pediatrics 2014, 133(2):211-218.

35. Cohen J: Statistical Power Analysis for Behavioral Sciences. New York: Academic Press; 1977.

36. van Koppen EJ, Schweizer JJ, Csizmadia CG, Krom Y, Hylkema HB, van Geel AM, Koopman HM, Verloove-Vanhorick SP, Mearin ML: Long-term health and quality-of-life consequences of mass screening for childhood celiac disease: a 10-year follow-up study. Pediatrics 2009, 123(4):e582-e588.

37. Kolsteren MM, Koopman HM, Schalekamp G, Mearin ML: Health-related quality of life in children with celiac disease. J Pediatr 2001, 138(4):593-595.

38. van Doorn RK, Winkler LM, Zwinderman KH, Mearin ML, Koopman HM: CDDUX: a disease-specific health-related quality-of-life questionnaire for children with celiac disease. J Pediatr Gastroenterol Nutr 2008, 47(2):147-152.

39. Wagner G, Berger G, Sinnreich U, Grylli V, Schober E, Huber WD, Karwautz A: Quality of life in adolescents with treated coeliac disease: influence of compliance and age at diagnosis. J Pediatr Gastroenterol Nutr 2008, 47(5):555-561.

40. Barratt SM, Leeds JS, Sanders DS: Quality of life in Coeliac Disease is determined by perceived degree of difficulty adhering to a gluten-free diet, not the level of dietary adherence ultimately achieved. J Gastrointestin Liver Dis 2011, 20(3):241-245.

41. Kurppa K, Lauronen O, Collin P, Ukkola A, Laurila K, Huhtala H, Maki M, Kaukinen K: Factors associated with dietary adherence in celiac disease: a nationwide study. Digestion 2012, 86(4):309-314.

42. Swedish National Institute of Public Health: Kartläggning av psykisk hälsa bland barn och unga. In Resultat från den nationella totalundersökningen i årskurs 6 och 9 hösten 2009. Upplaga 2. Östersund: Statens folkhälsoinstitut; 2011. Available at http://www.folkhalsomyndigheten.se.

43. Torsheim T, Currie C, Boyce W, Kalnins I, Overpeck M, Haugland S: Material deprivation and self-rated health: a multilevel study of adolescents from 22 European and North American countries. Soc Sci Med 2004, 59(1):1-12.

44. Myleus A, Hernell O, Gothefors L, Hammarstrom ML, Persson LA, Stenlund $H$, Ivarsson A: Early infections are associated with increased risk for celiac disease: an incident case-referent study. BMC Pediatr 2012, 12(1):194.

45. Wingren CJ, Bjorck S, Lynch KF, Ohlsson H, Agardh D, Merlo J: Coeliac disease in children: a social epidemiological study in Sweden. Acta Paediatr 2012, 101(2):185-191.
46. Ludvigsson JF: Socio-economic characteristics in children with coeliac disease. Acta Paediatr 2005, 94(1):107-113.

47. Olen O, Bihagen E, Rasmussen F, Ludvigsson JF: Socioeconomic position and education in patients with coeliac disease. Dig Liver Dis 2012, 44(6):471-476.

48. Hauser W, Stallmach A, Caspary WF, Stein J: Predictors of reduced health-related quality of life in adults with coeliac disease. Aliment Pharmacol Ther 2007, 25(5):569-578,

doi:10.1186/1471-2458-14-425

Cite this article as: Myléus et al:: Health-related quality of life is not impaired in children with undetected as well as diagnosed celiac disease: a large population based cross-sectional study. BMC Public Health 2014 14:425.

\section{Submit your next manuscript to BioMed Central and take full advantage of:}

- Convenient online submission

- Thorough peer review

- No space constraints or color figure charges

- Immediate publication on acceptance

- Inclusion in PubMed, CAS, Scopus and Google Scholar

- Research which is freely available for redistribution

Submit your manuscript at www.biomedcentral.com/submit
( Biomed Central 